Review

\title{
Endothelial Aging Associated with Oxidative Stress Can Be Modulated by a Healthy Mediterranean Diet
}

\author{
Carmen Marín ${ }^{\dagger}$, Elena M Yubero-Serrano ${ }^{\dagger}$, José López-Miranda and \\ Francisco Pérez-Jiménez *
}

Lipids and Atherosclerosis Unit, Maimonides Institute for Research in Biomedicina at Cordoba (IMIBIC)/Reina Sofia University Hospital/University of Cordoba and CIBER Fisiopatologia Obesidad y Nutricion (CIBERobn), Instituto de Salud Carlos III, Cordoba, 14004, Spain;

E-Mails: cmhinojo@yahoo.es (C.M.); helese35@hotmail.com (E.M.Y.-S.);

jlopezmir@gmail.com (J.L.-M.)

$\dagger$ These authors contributed equally to this work.

* Author to whom correspondence should be addressed; E-Mail: fperezjimenez@uco.es;

Tel.: +34-957-010-449; Fax: +34-957-218-251.

Received: 5 March 2013; in revised form: 28 March 2013 / Accepted: 2 April 2013 /

Published: 24 April 2013

\begin{abstract}
Aging is a condition which favors the development of atherosclerosis, which has been associated with a breakdown in repair processes that occurs in response to cell damage. The dysregulation of the biological systems associated with aging are produced partly through damage which accumulates over time. One major source of this injury is oxidative stress, which can impair biological structures and the mechanisms by which they are repaired. These mechanisms are based on the pathogenesis of endothelial dysfunction, which in turn is associated with cardiovascular disease, carcinogenesis and aging. The dependent dysfunction of aging has been correlated with a reduction in the number and/or functional activity of endothelial progenitor cells, which could hinder the repair and regeneration of the endothelium. In addition, aging, inflammation and oxidative stress are endogenous factors that cause telomere shortening, which is dependent on oxidative cell damage. Moreover, telomere length correlates with lifestyle and the consumption of a healthy diet. Thus, diseases associated with aging and age may be caused by the long-term effects of oxidative damage, which are modified by genetic and environmental factors. Considering that diet is a very important source of antioxidants, in this review we will analyze the relationship between oxidative stress, aging, and the mechanisms which may
\end{abstract}


be involved in a higher survival rate and a lower incidence of the diseases associated with aging in populations which follow a healthy diet.

Keywords: aging; oxidative stress; diet; telomeres; endothelial progenitor cell

\section{Introduction}

Aging is defined as the natural decline in chances of survival which all species suffer with advancing age. It is expected that in Europe, by 2025, the size of the elderly population will have reached 198 million, $78.5 \%$ more than in 1975 [1]. The dysregulation of the biological systems associated with aging are produced partly through damage that accumulates over time [2]. Understanding the molecular and cellular mechanisms that underlie the aging process would provide a good strategy to address the problems presented by the aging of the world's population.

Age-specific mortality rates from cardiovascular diseases (CVD) and strokes increase with age throughout the later years of life. Thus, the aging process is the main risk factor for the development of $\mathrm{CVD}$, and is associated with alterations of the structure and function of vascular components, such as the endothelium and vascular smooth muscle cells (VSMCs), through various pathways, including oxidative stress, cell senescence and inflammation [3-5].

Among the biological structures that are progressively affected by aging, the endothelium is one of the most important because it is in charge of the regulation of vascular homeostasis by the production of nitric oxide (NO) [6]. Previous evidence has demonstrated that in the absence of other risk factors, aging per se causes the development of atherosclerosis. Therefore, aging could be considered as an independent factor associated with endothelial dysfunction even in the absence of other cardiovascular risk factors such as hypertension, diabetes mellitus, hypercholesterolemia, cigarette smoking or a sedentary lifestyle, as well as genetic factors $[7,8]$.

Several studies suggest that the impairment of the endothelial function is a progressive, multifactorial phenomenon in the elderly, with several pathophysiological mechanisms contributing to the functional deterioration of vascular endothelial cells, and this is considered as one of the main processes by which aging increases the risk of CVD and the development of atherosclerosis in humans [9-11]. In this sense, there must be a balance between the rate of cellular damage and renewal to maintain homeostasis and tissue function. Therefore, the research approaches aimed at preserving or improving the endothelial function should play a key role in the prevention of vascular diseases in the elderly. One major mechanism involved in the vascular aging process is oxidative stress $[8,12]$. Considerable evidence has been published indicating that increased production of reactive oxygen species (ROS) leads to endothelial dysfunction in aging both in animals [13] and in humans [14]. However, several other possible mechanisms have been postulated: impairment of the NO pathway $[8,15,16]$, activation of inflammatory pathways [17-19], telomere length and telomerase activity [20,21], and the senescence of endothelial progenitor cells [22,23] (Figure 1). This complex process is controlled by several factors, such as changes in lifestyle, diet and physical activity, as well as drug treatments and medication [24-26] (Table 1). In this way, the use and application of these 
alternatives could prevent and/or treat advanced stages of endothelial dysfunction or act on the structural alterations of the vascular wall [27,28].

Figure 1. Postulated mechanisms involved in the vascular aging process. Vascular aging can be induced by different factors as oxidative stress, inflammation, an impairment of NO pathway and/or length and activity of telomerase, producing a decrease in cellular turnover mechanisms and an accumulation of senescent cells.

- Oxidative stress

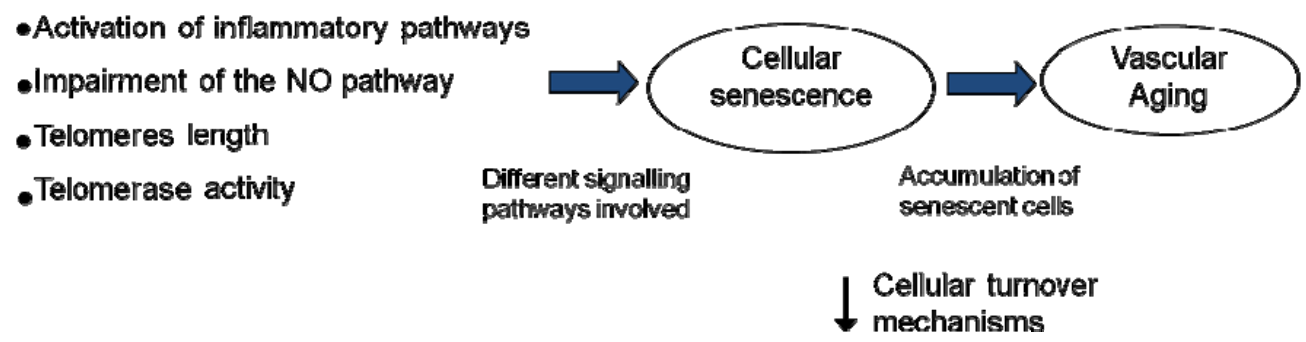

Table 1. Effect of dietary nutrients and caloric restriction on cellular damage associated with aging.

\begin{tabular}{|c|c|c|}
\hline Human Study & Mechanisms involved & Authors' conclusions \\
\hline Landberg et al. & Endothelial dysfunction & $\begin{array}{l}\text { Beneficial effects of dietary compounds, fruit, vegetables, fish } \\
\text { and nuts, on endothelial dysfunction [29] }\end{array}$ \\
\hline $\begin{array}{l}\text { Kiecolt-Glaser, J.K. } \\
\text { et al. }\end{array}$ & $\begin{array}{l}\text { Telomere length and } \\
\text { Inflammation }\end{array}$ & $\begin{array}{c}\text { The lower n-6: n-3 (polyunsaturated fatty acid) PUFA ratios } \\
\text { may be beneficial for slowing biological } \\
\text { aging }[30,31]\end{array}$ \\
\hline Weiss, E.P. et al. & Vascular aging & $\begin{array}{l}\text { Studies in animals and humans indicate that caloric restriction } \\
\text { prevent many of the age-related changes in the structure and } \\
\text { function of the cardiovascular system [32] }\end{array}$ \\
\hline Scoditti, E. et al. & Inflammation & $\begin{array}{c}\text { Mediterranean diet polyphenols suppressed inflammatory } \\
\text { angiogenesis [33] }\end{array}$ \\
\hline Mirabello, L. et al. & Telomere length & $\begin{array}{l}\text { A healthy lifestyle with a diet high in fruit and vegetables } \\
\text { combined with exercise, lower body mass and not smoking is } \\
\text { associated with longer telomeres [34] }\end{array}$ \\
\hline Marin, C. et al. & $\begin{array}{l}\text { Endothelial progenitor cell, } \\
\text { microparticles, oxidative } \\
\text { stress and telomere length }\end{array}$ & $\begin{array}{l}\text { The Mediterranean diet is associated with improvement in } \\
\text { endothelial regeneration capacity, increased number of } \\
\text { circulating endothelial progenitors cell (EPC), lower levels of } \\
\text { microparticles, reduce oxidative stress and decreased telomere } \\
\text { shortening rate }[35,36]\end{array}$ \\
\hline Fernandez, J.M. et al. & Endothelial progenitor cell & $\begin{array}{l}\text { The consumption of a Mediterranean diet and exercise led a } \\
\text { greater decrease in blood pressure and a greater increase in } \\
\text { EPC number [37] }\end{array}$ \\
\hline Martinez, P. et al. & Markers of oxidative stress & $\begin{array}{l}\text { The Mediterranean diet reduces postprandial levels of } \\
\text { oxidative stress biomarkers such as lipid peroxide, protein } \\
\text { carbonyl, superoxide dismutase (SOD) activity and plasma } \\
\qquad \mathrm{H}_{2} \mathrm{O}_{2}[38]\end{array}$ \\
\hline
\end{tabular}


Table 1. Cont.

\begin{tabular}{|c|c|c|}
\hline Human Study & Mechanisms involved & Authors' conclusions \\
\hline Cruz-Teno, C. et al. & Inflammatory state & $\begin{array}{l}\text { The Mediterranean diet attenuates the postprandial } \\
\text { inflammatory state, including nuclear transcription } \\
\text { factor-kappa B (NF- } \kappa \mathrm{B}) \text {, metalloproteinase-9 and tumor } \\
\text { necrosis factor- } \alpha \text { [39] }\end{array}$ \\
\hline Cassidy, A. et al. & Telomere length & $\begin{array}{l}\text { The dietary intake of fiber is positively correlated with } \\
\text { leukocyte telomere length in women and negatively associated } \\
\text { with dietary intake of polyunsaturated fatty acids, especially } \\
\text { linoleic acid [40] }\end{array}$ \\
\hline $\begin{array}{l}\text { Farzaneh-Far, E. et al. } \\
\text { Kielcolt-Glaser, J.K. } \\
\text { et al. }\end{array}$ & Telomere shortening & $\begin{array}{l}\text { In patients with coronary artery disease, there was an inverse } \\
\text { relationship between baseline blood levels of marine omega-3 } \\
\text { fatty acids and the rate of telomere shortening }[31,41]\end{array}$ \\
\hline $\begin{array}{l}\text { Yubero-Serrano, E.M. } \\
\qquad \text { et al. }\end{array}$ & Oxidative stress & $\begin{array}{l}\text { The Mediterranean diet, rich in virgin olive oil, induced a } \\
\text { reduction in the degree of oxidative stress. In addition, } \\
\text { coenzyme Q10 supplementation can improve antioxidant } \\
\text { activity of cell membranes in the elderly }[24,25]\end{array}$ \\
\hline Animal model study & Mechanisms involved & Author's conclusion \\
\hline Jung, K.J. et al. & Inflammation & $\begin{array}{l}\text { Caloric restriction appears to attenuate vascular NF- } \kappa \mathrm{B} \\
\text { induction and endothelial activation in aged rats }[42,43]\end{array}$ \\
\hline McCarty, M.F. & Nitric oxide production & $\begin{array}{l}\text { A low-fat, whole-food, vegan diet or exercise training would } \\
\text { be expected to decrease the risk of common age-related } \\
\text { diseases [26] }\end{array}$ \\
\hline In vitro study & Mechanisms involved & \begin{tabular}{|l} 
Author's conclusion \\
\end{tabular} \\
\hline Csiszar, A. et al. & Mitochondria & $\begin{array}{c}\text { Resveratrol induces mitochondrial biogenesis in cultured } \\
\text { endothelial cells and in endothelia of mice with accelerated } \\
\text { vascular aging }[22,27]\end{array}$ \\
\hline $\begin{array}{l}\text { Csiszar, A. et al. and } \\
\text { Ungvari, Z. et al. }\end{array}$ & $\begin{array}{l}\text { Inflammation and oxidative } \\
\text { stress }\end{array}$ & $\begin{array}{l}\text { In vitro studies suggest that the molecular mechanisms of } \\
\text { resveratrol-mediated vasoprotection involve an inhibition of } \\
\text { NF- } \mathrm{BB} \text { and an upregulation of endothelial nitric oxide synthase } \\
\text { (eNOS) and antioxidant enzymes }[28,44-46]\end{array}$ \\
\hline Tang, Y. et al. & $\begin{array}{l}\text { Cellular senescence and } \\
\text { oxidative stress }\end{array}$ & $\begin{array}{l}\text { In vitro studies suggest that resveratrol protects vascular cell } \\
\text { senescence reducing the production of reactive oxygen species } \\
\text { (ROS) }[23,28]\end{array}$ \\
\hline
\end{tabular}

Greater knowledge of the molecular and cellular mechanisms involved in vascular dysfunction associated with aging would provide a better understanding with which we could develop suitable strategies, use specific targets to mitigate the effect of vascular aging, prevent cardiovascular diseases and improve the quality of life of the elderly. After that, we will analyze the mechanisms involved in vascular dysfunction related with aging and review the possible benefits of dietetic strategies with potential to promote cardiovascular health in the elderly.

For this review, we have carried out a systematic search of the Pubmed database from 1990 to February 2013. The keywords used in the Pubmed search were "aging, oxidative stress, vascular aging, diet and Mediterranean diet." Our search strategy yielded 13,078 citations. Irrelevant papers were excluded by title and abstract reviews, which narrowed it down to 126 manuscripts. We reviewed 
scientific articles considering the scientific evidence that included: (1) The effect of oxidative stress on vascular aging; (2) the effect of nutrients and dietary intervention on vascular aging; (3) repairing the damage induced by oxidative stress and the inflammatory process in aging.

\section{Vascular Aging and Oxidative Stress}

The underlying mechanisms in vascular aging are complex, and involve different pathways [47]. Oxidative stress is caused by an imbalance between the production of reactive oxygen and a biological system's ability to readily detoxify the reactive intermediates or easily repair the resulting damage. A large body of evidence indicates that oxidative stress is increased during aging, which is caused by the imbalance between ROS production and antioxidant defense capability (enzymatic and non-enzymatic antioxidants) [12]. Various hypotheses suggest that the decline in endothelial function during aging is due to an increase in superoxide anion $\left(\mathrm{O}_{2}{ }^{-}\right)$levels, which lead to a decrease in the availability of NO [48].

The main sources of ROS in the endothelium are composed of a variety of cell types, including VSMCs, endothelial cells and mononuclear cells. ROS include superoxide anion $\left(\mathrm{O}_{2}{ }^{-}\right)$, hydrogen peroxide $\left(\mathrm{H}_{2} \mathrm{O}_{2}\right)$, hydroxyl radical $(\mathrm{OH})$, hypochlorous acid $(\mathrm{HOCl}), \mathrm{NO}$ and peroxynitrite $\left(\mathrm{ONOO}^{-}\right)$. The antioxidant enzyme superoxide dismutase (SOD) rapidly dismutates $\mathrm{O}_{2}{ }^{-}$to $\mathrm{H}_{2} \mathrm{O}_{2}$, and subsequently, the $\mathrm{H}_{2} \mathrm{O}_{2}$ is eliminated by glutathione peroxidase ( $\left.\mathrm{GSH}-\mathrm{Px}\right)$ and catalase and turned into water.

Aging activates the enzymes involved in ROS production, such as nicotinamide adenine dinucleotide phosphate (NADPH) oxidase, xantine oxidase, uncoupled NO synthase and cyclooxygenase and it inactivates the antioxidant system, including SOD, (GSH-Px) and catalase, leading to an increase in ROS production and a decrease in ROS degradation. However, the results obtained from different studies in which antioxidant defense levels were determined were contradictory. While some authors observed an age-related decrease in superoxide dismutase (SOD) and glutathione peroxidase (GSH-Px) activities and a decline in plasma antioxidant capacity [46], others found an increase in the activity of SOD and GSH-Px [49].

Another source for aging-induced vascular dysfunction is oxidative stress generated by mitochondria [44]. Under physiological conditions, mitochondria produce $\mathrm{O}_{2}{ }^{-}$and $\mathrm{H}_{2} \mathrm{O}_{2}$, so that mitochondrial DNA (mtDNA) is particularly exposed to oxidative damage. During aging, the result is a reduction in the number of mitochondria and a higher expression of dysfunctional proteins, which leads to the malfunction of the respiratory chain energy, increasing $\mathrm{O}_{2}{ }^{-}$production and a depletion in energy supply to cells [50].

The implication of oxidative stress in the development of vascular aging has been described in both laboratory animals $[51,52]$ and humans [14,53]. Upregulation of pro-oxidants and downregulation of antioxidants leads to consequences in vascular remodeling by VSMCs proliferation, migration and extracellular matrix remodeling [54], generating an impairment of endothelial function, inflammation, apoptosis and senescence of endothelial cells [55].

\section{Vascular Aging and Inflammation}

Abundant experimental and clinical data show that aging is also associated with chronic low-grade inflammation. Because there is an important cross talk among inflammatory processes, generation of 
ROS and endothelial dysfunction [56], recent studies showed that ROS per se can act as molecule-signaling activating pathways which regulate inflammatory processes, including secretion of inflammatory mediators. Inflammation itself promotes cellular oxidative stress [53]. ROS interacts with different redox-sensitive transcriptional factors such as activator protein 1 (AP-1) and nuclear transcription factor-kappa B (NF- $\kappa \mathrm{B})$, increasing the gene expression of cytokines (TNF $\alpha$, IL-1 $\beta$ and IL-6) and adhesion molecules (Intercellular Adhesion Molecule 1 (ICAM-1) and vascular cell adhesion protein 1 (VCAM-1)). An increase in inflammatory cytokine levels contributes to a pro-inflammatory status, facilitates the development of vascular dysfunction, and promotes endothelial apoptosis in aging [57]. In this regard, it is significant that caloric restriction can attenuate the altered signaling transduction of inflammatory processes, which are mediated through NF- $\mathrm{KB}$ and AP-1, and endothelial activation in aged rats [42,43,58]. Furthermore, it has numerous beneficial effects on the aging cardiovascular system by a reduction in the inflammatory process in the vasculature and heart, and it could protect against the development of arterial stiffness with increasing aging [32].

\section{Vascular Aging and Alteration of the NO Pathway}

Nitrosative stress is defined as the ratio of nitrosants and antioxidants similar to oxidative stress, but with the additional involvement of reactive nitrogen species. Oxidative/nitrosative stress represent the imbalance in the production and the elimination of reactive oxygen and nitrogen species. Many functions of the vascular endothelium are modulated by NO, which is able to confer vasoprotective and cardioprotective effects, including the production of smooth muscle relaxation [10]; inhibition of platelet activation and adhesion to the surface of the endothelium [59]; disruption of synthesis and expression of cytokines and cell adhesion molecules [47]; preservation of endothelial progenitor cell (EPC) function; and regulation of tissue energy metabolism. NO is synthesized from L-arginine by the enzyme NO synthase (NOS). There are three known NOS isoenzymes: the constitutive endothelial (eNOS) and neuronal (nNOS) isoforms, which produce the NO involved in regulatory pathways, and the inducible (iNOS) NOS isoform, which produces an uncontrolled NO synthesis, related with inflammatory responses. As we mentioned previously, the reduction of NO availability caused by excess ROS production is a major cause of endothelial dysfunction in aging, altering vascular homeostasis [60,61]. This reduced NO production may be controlled by several mechanisms: (1) a deficiency in NOS substrates and cofactors; (2) the presence of endogenous eNOS inhibitors; and (3) a lower expression and/or activity of eNOS.

\subsection{Deficiency in NOS Substrates and Cofactors}

One of the mechanisms responsible for a low NO availability during aging is the presence of a lower concentration of L-arginine, which is used as eNOS substrate to produce NO in endothelial cells. The oxidation of L-arginine produces NO and L-citruline by endothelial nitric oxide synthase (eNOS) (Figure 2) [62]. The contribution of an increased expression and/or activity of arginase, the enzyme that degrades L-arginine, to age-related endothelial dysfunction could explain a decrease in substrate availability for eNOS and the consequent reduction of NO synthesis [63]. This is not the only mechanism that leads to impaired NO production, but it also contributes to an enhanced production of ROS by NOS (Figure 2). Although the role of arginase in endothelial dysfunction in elderly patients 
requires further investigation, some studies suggest that this alteration described in animals might also appear in humans [64].

Figure 2. Mechanisms responsible for a low NO availability during aging. The oxidation of L-arginine produces NO and L-citruline by the endothelial nitric oxide synthase (eNOS). The presence of low levels of L-arginine contribute to a low NO availability during aging.

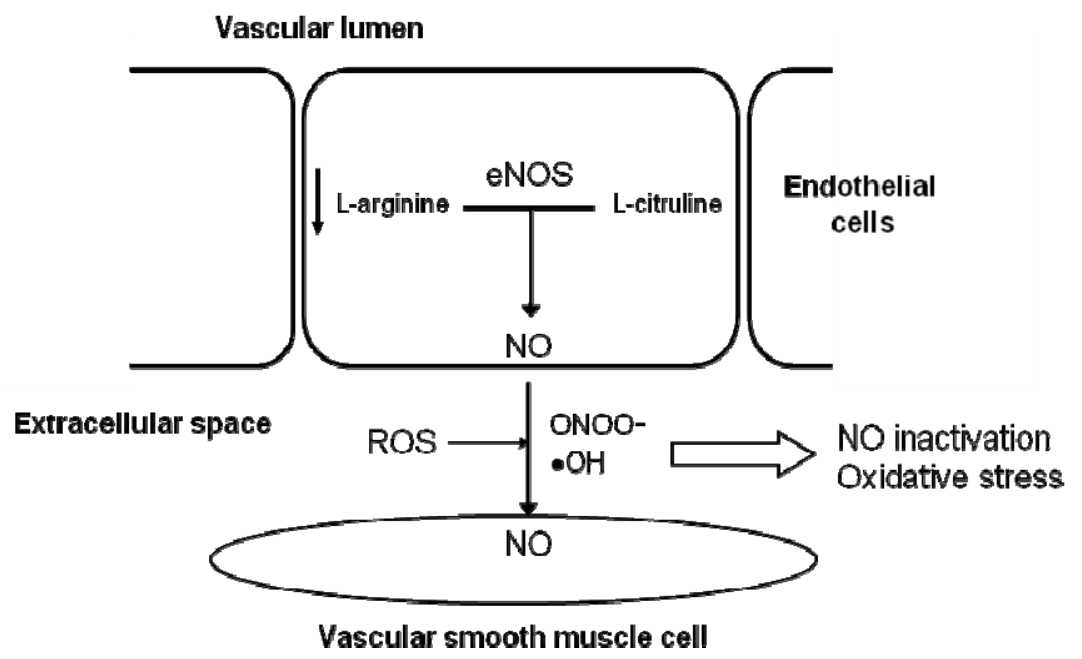

Tetrahydrobiopterin $\left(\mathrm{BH}_{4}\right)$, a cofactor essential for NOS activity, is an allosteric factor in the coupling of the oxidase and reductase domains of eNOS [65]. The regulation of eNOS by the oxidation of the cofactor $\mathrm{BH} 4$ is an important contributor to endothelial dysfunction. ROS induces eNOS uncoupling, altering its catalytic activity. eNOS uncoupling produces ROS rather than NO, and therefore, when BH4 is limited or under oxidative stress conditions, this cofactor produces superoxide, leading to peroxinitrite $[65,66]$. Several studies have shown that the administration of BH4 to older adults causes a selective improvement in endothelial vasorelaxation, demonstrating that BH4 potentially leads to eNOS recoupling in aged human vasculature [67].

\subsection{Presence of Endogenous eNOS Inhibitors}

An endogenous L-arginine analog, asymmetric dimethylarginine (ADMA), blocks the synthesis of NO by the inhibition of the NOS active site. ADMA is a naturally occurring amino acid found in plasma and various tissues. An enhanced production of ADMA has been associated with impaired endothelial function in humans [68]. A possible role for this compound has been proposed in the physiological process of aging, as a positive correlation has been reported in healthy subjects between the plasmatic levels of ADMA and age [69]. Moreover, the effect ADMA has on accelerating endothelial cells senescence has been previously described [70].

\subsection{Lower Expression and/or Activity of eNOS}

Several studies have evaluated the expression of the enzyme eNOS in arteries of aged animals, but the results obtained have not provided definitive conclusions. While some studies, performed in smooth muscle cells, showed increased eNOS protein levels in the aorta and mesenteric arteries [71], others have reported no significant changes in eNOS expression in the same cellular type [72]. In 
human endothelial cells from peripheral veins and the brachial artery, there were no changes in eNOS expression during the aging process [73]. The discrepancies found among the published results could be due to the use of different animal models, arterial types (in human or animals) and the difference in age between old and young groups; however, there is a greater consensus over the reduced activity of the eNOS enzyme in aging [74]. Also, eNOS is regulated at post-transcriptional level involving PI3 kinase/Akt-dependent phosphorylation at Ser117, resulting in an increase in NO production from endothelial cells. In aged animals, the PI3K/Akt pathway is diminished and eNOS gene expression and enzymatic activity levels decrease [75]. However, the involvement in this low rate of eNOS phosphorylation in human vascular aging needs to be confirmed.

\section{Vascular Aging and Cellular Senescence}

Considerable evidence indicates that an imbalance between the magnitude of vascular injury and the capacity for repair appears to play an important role in age-related impaired endothelial function. These impairments are attributed to a decrease in the number and function of endothelial progenitor cells (EPCs) and/or impaired cell replication.

\subsection{Number and Function of Endothelial Progenitor Cells (EPCs)}

Accumulating evidence suggests that circulating bone marrow-derived EPCs contribute to vascular repair and regeneration, accelerating re-endothelialization and protecting against the initiation and progression of atherosclerosis [76]. EPCs express markers of both hematopoietic stem cells and endothelial cells on their surface and represent a very small subset of mononuclear cells, between $0.002 \%$ and $0.01 \%$ in peripheral blood and $0.2 \%-1 \%$ in umbilical cord blood [77]. Circulating EPC levels reflect vascular repair capacity, so that a reduction in the number of circulating EPCs predicts the occurrence of cardiovascular events [76]. In this situation, EPCs are mobilized from the bone marrow into circulation, reaching vascular injury areas where they are able to contribute to new blood vessel formation. Several studies have demonstrated that circulating EPCs are subject to changes associated with aging, which negatively affect their number and/or function. Consistent with this notion, the number of EPCs in healthy individuals is reduced with age [78]. Also, EPC mobilization is significantly impaired in older individuals compared with younger subjects [79] and the function of EPCs from older individuals also appears to be disrupted, according to in vitro studies [80]. Moreover, flow-mediated vasodilation was significantly correlated with the number of circulating EPCs in patients who had varying degrees of cardiovascular risk (but no history of cardiovascular disease) [81].

There is a wide range of environmental factors which influence EPC generation and function. Previous studies demonstrated that human EPCs express high levels of antioxidant enzymes as compared to mature endothelial cells [82]. Aging produces an impairment of their antioxidant capacity, reducing levels and activity of antioxidant enzymes such as glutathione peroxidase-1 [82].

Aging is also known to be associated with the development of chronic low grade inflammation, which contributes to impaired EPC function [56]. Deregulation of the pro-inflammatory cytokine TNF- $\alpha$ has been associated with the pathogenesis of atherosclerosis. Indeed, vascular aging is associated with upregulation of TNF- $\alpha$, which can induce premature senescence in highly proliferative EPCs [83]. A decrease in EPC mobilization and function may be related to the reduced capacity of the 
aging endothelium to generate NO and the increased production of ROS [84]. The accumulation of oxidized low-density lipoprotein (oxLDL) with age also contributes to a reduction in the number of circulating EPCs, due to its inhibitory effect on eNOS expression and activity [85]. Another factor involved in EPC regeneration during aging is endothelial senescence, a process through which the EPC vascular repair mechanisms are damaged. The therapeutic use of the introduction of telomerase into EPCs has been shown to extend lifespan and improve vasculogenesis of these cells [86].

\subsection{Impaired Cell Replication and Telomere Shortening in Aged Arteries}

Telomeres are repeats of DNA-protein complexes, located at the ends of chromosomes, and are essential to the stability of chromosome and cell replication. The formation, maintenance and repair of telomeres are performed by the enzyme telomerase, but as a consequence of semiconservative DNA replication, the extreme terminals of chromosomes are not duplicated completely, causing successive shortening of the telomeres with each round of cell division [87]. Telomere length is regulated by pro-inflammatory cytokines and oxidative stress [88,89]: the latter promotes telomere shortening during cell replication in vitro and stimulates the synthesis of pro-inflammatory cytokines [20]. There is evidence of a correlation between ROS levels and the rate of telomere shortening. These studies suggest that an increase in intracellular ROS level could lead to an acceleration in the rate of telomere shortening. The progressive shortening of telomeres leads to senescence, apoptotic cell death, or the oncogenic transformation of somatic cells in various tissues. Telomere length, which can be affected by various lifestyle factors, may determine overall health, lifespan, and the rate at which an individual ages [90].

As a normal cellular process, telomere length decreases with age [91]. Recent studies in rodents have shown a causal effect of telomerase deficiency and telomere shortening on healthy aging and premature mortality $[92,93]$. Similarly, the length of telomeres isolated from endothelial cells of human arteries shows a strong inverse correlation with age [88]. The endothelial cell senescence observed during the normal aging process seems to be accelerated in the diseases associated with aging and in particular CVD [94].

\subsection{Microparticles}

Microparticles (MPs) are small fragments or vesicles from different types of cells (endothelial cells, platelets and leukocites) which are released during cell apoptosis, inflammatory activation and cellular stress [95]. They are made up of material from their cells of origin, which is a general characteristic of MPs [96]. MPs are present in plasma from healthy subjects, but their concentrations change in several clinical conditions. MP concentrations increase in patients with cardiovascular risk factors and after cardiovascular events [97]. Moreover, certain pharmacological treatments, used to treat cardiovascular diseases, reduce plasma MP concentrations. However, the pathophysiological effects of MPs in vivo are still poorly understood. Studies performed with MPs (in vitro or isolated ex vivo) have shown that they can influence some of the processes involved in atherogenesis, such as endothelial function, angiogenesis, inflammation and thrombosis, which suggests that MPs are not only markers, but they are also involved in cardiovascular diseases [98].

Several studies have reported an increase in MPs in aged diabetic rats [99] and an increase in leukocyte-derived MPs in aged mice with thrombosis [100]. In humans, there is an increase in 
platelet-derived MPs in the elderly compared to healthy individuals [101]. All these findings show the role of MPs in vascular pathology and suggest that, by themselves, they are the key to promoting premature vascular aging cellular senescence.

Recent studies have indicated that MPs have an effect on the endothelium through the increase in oxidative stress and endothelial inflammation, reducing the production of NO, or stimulating the platelet and macrophage adhesion to endothelial cells [102-104]. Burger et al. [104] have observed that MPs stimulate the production of ROS through NADPH oxidase [105], mitochondria, and NOS ciclooxigenase [106], inducing premature senescence of the endothelial cells. These results suggest that MPs contribute to the progression of vascular aging mechanism through a "feed-forward" method, where the increased formation of MPs from senescent endothelial cells also promotes cellular senescence through an increase in ROS production.

\section{Mediterranean Diet: Does It Prevent Endothelial Aging?}

The Mediterranean diet is a healthy diet which includes fish, vegetables, fruit, whole grains, legumes, olive oil, and less red meat and dairy products. Changes in lifestyle habits, such as diet and moderate exercise, can influence vascular repair mechanisms. Different studies have shown that a healthy diet and exercise induce a reduction in cell damage and endothelial dysfunction, both of which are factors responsible for reducing cardiovascular risk in the elderly [24,107].

Several intervention studies have suggested that the consumption of flavonoid-rich foods such as tea, red wine [108], cocoa and soya can improve endothelial function in patients with manifest cardiovascular and cerebrovascular disease $[109,110]$. In this way, Perez-Martinez et al., showed that the consumption of a Mediterranean diet reduced postprandial levels of oxidative stress biomarkers such as lipid peroxide, protein carbonyl, SOD activity and plasma $\mathrm{H}_{2} \mathrm{O}_{2}$ compared to a saturated fat-rich diet in metabolic syndrome subjects [38]. Similarly, this diet significantly attenuated the postprandial inflammatory state, including NF- $\kappa \mathrm{B}$, metalloproteinase- 9 and tumor necrosis factor- $\alpha$ [33,39]. In addition, consumption of a Mediterranean diet and exercise led to a greater decrease in blood pressure and a greater increase in the number of EPC compared with the same diet without exercise [37].

Antioxidant supplementation can play an important role in delaying or reducing many of the adverse effects of aging. In this regard, it is interesting to review the beneficial effects that can be obtained through nutrition in the prevention of the deleterious effects induced by oxidative stress. The repair or prevention effects have been attributed to the presence of antioxidants, mainly contained in plant foods such as fruit, vegetables, whole grains, nuts and seeds [29,111,112]. Several studies indicate that vitamin E supplementation can improve antioxidant activity of cell membranes in elderly subjects [113,114]. Also, antioxidants such as the polyphenolic compound have anti-aging properties. In addition, a recent randomized controlled trial has shown that omega-3-polyunsaturated fatty acid supplementation lowered the concentration of serum pro-inflammatory cytokines [30]. On the other hand, Csiszar et al. indicated the possibility that supplementation of resveratrol, a diet-derived polyphenol, may confer significant vasoprotection in elderly humans $[45,115,116]$.

Similarly, studies performed with elderly people have demonstrated that the consumption of a Mediterranean diet produced an increase in NO bioavailability, with a consequent improvement in 
endothelium-dependent endothelial function [25]. It is also associated with an improvement in endothelial regeneration capacity, producing an increased number of circulating EPCs and lower levels of microparticles, compared with the consumption of a saturated fatty acid-rich diet and a low-fat and high-carbohydrate diet, enriched with $\alpha$-linolelic acid [35,37].

An improvement in lifestyle habits is also positively correlated with telomere length. In fact, telomere length has been associated with nutritional status in both human and animal models (Table 1). A healthy lifestyle, with a diet high in fruit and vegetables combined with exercise, lower body mass and not smoking is associated with longer telomeres [34]. Another study suggests that lower n-6:n-3 PUFA ratios can influence cell aging, increasing telomere length with a reduction of the n-6:n-3 ratio in a diet supplemented with omega-3 (n-3) PUFA [31]. A protein-restricted diet produced an increase in lifespan and a reduction in growth rate in rats, but also, the increased lifespan in such animals was associated with significantly longer telomeres in the kidney [117]. Cassidy et al. [40] demonstrated that leukocyte telomere length in women was positively correlated with dietary intake of fiber and negatively associated with dietary intake of polyunsaturated fatty acids, especially linoleic acid. Recent studies have shown that, in patients with coronary artery disease, there was an inverse relationship between baseline blood levels of marine omega-e fatty acids and the rate of telomere shortening [41]. Similarly, there is evidence to show the effect of the quality and quantity of dietary fat on telomere length, depending on the degree of oxidative stress that these diets produce. Therefore, the consumption of a saturated fatty acid-rich diet or a carbohydrate-rich diet induces telomere attrition, as a result of cell replication, which can be accelerated by the presence of increased oxidative stress [36]. However, the consumption of a Mediterranean type diet (monounsaturated fat-rich diet), rich in virgin olive oil, improves this profile and leads to a reduction in the degree of oxidative stress [24,25] and a decrease in the rate of telomere shortening [35]. Antioxidants can potentially protect telomeric DNA from oxidative damage caused by extrinsic and intrinsic DNA damaging agents, so a diet lacking antioxidants led to shorter telomeres, whereas consumption of an antioxidant rich diet such as vitamin $\mathrm{C}, \mathrm{E}$ and $\beta$-carotene was associated with longer telomeres $[35,118]$.

\section{Conclusions and Future Expectations}

Healthy dietary habits and moderate physical exercise improve endothelial dysfunction and oxidative stress, which are two factors involved in cardiovascular alterations associated with vascular aging. The consumption of a Mediterranean diet improves endothelial regenerative capacity as a result of a balance between cellular damage and repair. The mechanisms involved in this process can be associated with a decreased release of free radicals and a reduction in oxidative stress, due to the protective effects of both the monounsaturated fat and antioxidants present in this diet. Moreover, a Mediterranean diet may protect against endothelial cell senescence, generating a decrease in intracellular oxidative stress, telomere shortening and cellular apoptosis. All these mechanisms may be involved in an increased lifespan and a lower incidence of the diseases associated with aging present in populations which consume a Mediterranean-type diet.

These findings show that cellular oxidative stress, one of the major sources of damage in the dysregulation of biological systems, is closely linked to the generation of ROS and this can contribute to the development of cellular senescence, which leads to accelerated aging of the organism [119]. 
Senescent endothelial cells play a more important role morphologically and functionally in the development of atherosclerosis than normal cells. Epidemiological data indicate that young subjects with early signs of vascular senescence have an increased risk of developing CVD, so this suggests that the prevention or delay of the aging process could be used as a prophylaxis of vascular aging.

Antioxidant supplementation can play an important role in delaying or reducing many of the adverse effects of aging. Its repair or prevention effects have been attributed to the presence of antioxidants, mainly contained in plant foods such as fruit, vegetables, whole grains, nuts and seeds. Several studies have indicated that vitamin E and/or coenzyme $\mathrm{Q}_{10}$ supplementation can improve antioxidant activity of cell membranes in the elderly [24,25,120].

Dietary fat may also modulate oxidative stress in human endothelial cells, and a Mediterranean diet may bring considerable health benefits. Esposito et al. [121] have shown that in overweight or obese men, a prolonged adherence to a Mediterranean-style diet with or without caloric restriction, is associated with amelioration of multiple risk factors including a better cardiovascular risk profile and a reduced level of oxidative stress, all of which are markers of aging. Several researchers have suggested that the Mediterranean diet has a protective effect against cardiovascular, metabolic, cancer and other age-related diseases and degenerative diseases [24,25,122,123]. The Mediterranean dietary pattern is characterized by a high intake of fruit and vegetables, olive oil as the main source of fat intake, a low consumption of meat products, and moderate wine consumption. Visioli et al. [124] have linked the benefits of the Mediterranean diet with the protective role of phenolic compounds present in this type of diet, leading to a reduction of oxidative stress. Recent studies performed in the elderly have demonstrated that the Mediterranean diet protected endothelial cells against oxidative stress and prevented the development of cell senescence [35]. This study has shown that the consumption of a Mediterranean diet induces lower intracellular oxidative stress by decreasing levels of ROS. Therefore, this diet could modulate intracellular oxidative stress in the elderly, possibly due to minor components with antioxidant properties included in the Mediterranean diet. Recent studies confirm that excessive oxidative stress on endothelial cells promotes apoptosis [125]. Thus, the Mediterranean diet and/or the micronutrients present in this diet may participate in the regulation of these pathways, leading to lower apoptosis in endothelial cells [35].

In summary, dietary intervention, and particularly a Mediterranean-style diet, improves vascular dysfunction and microcirculation, and can play a role in the protection against the chronic diseases related to aging.

\section{Acknowledgments}

CIBEROBN is an initiative of the Instituto de Salud Carlos III, Madrid, Spain, partly supported by public funds: research grants from the Spanish Ministry of Science and Innovation (AGL2006-01979 and AGL2009-12270 to J L-M, SAF07-62005 and PI10/02412 to F P-J and P11/00185 to CM); Consejería de Economía, Innovación y Ciencia, Proyectos de Investigación de Excelencia, Junta de Andalucía (P06-CTS-01425 to J L-M, CTS5015 and AGR922 to F P-J); Consejería de Salud, Junta de Andalucía (PI0193/09 to J L-M), and Fondo Europeo de Desarrollo Regional (FEDER). 


\section{Conflict of Interest}

The authors declare no conflict of interest.

\section{References}

1. Mirea, O.; Donoiu, I.; Plesea, I.E. Arterial aging: A brief review. Rom. J. Morphol. Embryol. 2012, 53, 473-477.

2. Sohal, R.S.; Mockett, R.J.; Orr, W.C. Mechanisms of aging: An appraisal of the oxidative stress hypothesis. Free Radic Biol. Med. 2002, 33, 575-586.

3. Ferrari, A.U.; Radaelli, A.; Centola, M. Invited review: Aging and the cardiovascular system. J. Appl. Physiol. 2003, 95, 2591-2597.

4. Panza, J.A.; Quyyumi, A.A.; Brush, J.E., Jr.; Epstein, S.E. Abnormal endothelium-dependent vascular relaxation in patients with essential hypertension. N. Engl. J. Med. 1990, 323, 22-27.

5. Yildiz, O. Vascular smooth muscle and endothelial functions in aging. Ann. N. Y. Acad. Sci. 2007, 1100, 353-360.

6. Moncada, S.; Higgs, A. The L-arginine-nitric oxide pathway. N. Engl. J. Med. 1993, 329, 2002-2012.

7. Barodka, V.M.; Joshi, B.L.; Berkowitz, D.E.; Hogue, C.W., Jr.; Nyhan, D. Review article: Implications of vascular aging. Anesth. Analg. 2011, 112, 1048-1060.

8. Rodriguez-Manas, L.; El-Assar, M.; Vallejo, S.; Lopez-Doriga, P.; Solis, J.; Petidier, R.; Montes, M.; Nevado, J.; Castro, M.; Gomez-Guerrero, C.; et al. Endothelial dysfunction in aged humans is related with oxidative stress and vascular inflammation. Aging Cell 2009, 8, 226-238.

9. Irani, K. Oxidant signaling in vascular cell growth, death, and survival : A review of the roles of reactive oxygen species in smooth muscle and endothelial cell mitogenic and apoptotic signaling. Circ. Res. 2000, 87, 179-183.

10. Seals, D.R.; Jablonski, K.L.; Donato, A.J. Aging and vascular endothelial function in humans. Clin. Sci. 2011, 120, 357-375.

11. Lloyd-Jones, D.; Adams, R.J.; Brown, T.M.; Carnethon, M.; Dai, S.; de Simone, G.; Ferguson, T.B.; Ford, E.; Furie, K.; Gillespie, C.; et al. Heart disease and stroke statistics-2010 update: A report from the American Heart Association. Circulation 2010, 121, e46-e215.

12. Ungvari, Z.; Kaley, G.; de Cabo, R.; Sonntag, W.E.; Csiszar, A. Mechanisms of vascular aging: New perspectives. J. Gerontol. A 2010, 65, 1028-1041.

13. Van der Loo, B.; Labugger, R.; Skepper, J.N.; Bachschmid, M.; Kilo, J.; Powell, J.M.; Palacios-Callender, M.; Erusalimsky, J.D.; Quaschning, T.; Malinski, T.; et al. Enhanced peroxynitrite formation is associated with vascular aging. J. Exp. Med. 2000, 192, 1731-1744.

14. Donato, A.J.; Eskurza, I.; Silver, A.E.; Levy, A.S.; Pierce, G.L.; Gates, P.E.; Seals, D.R. Direct evidence of endothelial oxidative stress with aging in humans: Relation to impaired endothelium-dependent dilation and upregulation of nuclear factor-kappaB. Circ. Res. 2007, 100, $1659-1666$.

15. Toda, N. Age-related changes in endothelial function and blood flow regulation. Pharmacol. Ther. 2012, 133, 159-176. 
16. Virdis, A.; Ghiadoni, L.; Giannarelli, C.; Taddei, S. Endothelial dysfunction and vascular disease in later life. Maturitas 2010, 67, 20-24.

17. D'Alessio, P. Aging and the endothelium. Exp. Gerontol. 2004, 39, 165-171.

18. Ferrucci, L.; Corsi, A.; Lauretani, F.; Bandinelli, S.; Bartali, B.; Taub, D.D.; Guralnik, J.M.; Longo, D.L. The origins of age-related proinflammatory state. Blood 2005, 105, 2294-2299.

19. Ungvari, Z.; Csiszar, A.; Kaminski, P.M.; Wolin, M.S.; Koller, A. Chronic high pressure-induced arterial oxidative stress: Involvement of protein kinase C-dependent NAD(P)H oxidase and local renin-angiotensin system. Am. J. Pathol. 2004, 165, 219-226.

20. Minamino, T.; Komuro, I. Role of telomeres in vascular senescence. Front. Biosci. 2008, 13, 2971-2979.

21. Ogami, M.; Ikura, Y.; Ohsawa, M.; Matsuo, T.; Kayo, S.; Yoshimi, N.; Hai, E.; Shirai, N.; Ehara, S.; Komatsu, R.; et al. Telomere shortening in human coronary artery diseases. Arterioscler. Thromb. Vasc. Biol. 2004, 24, 546-550.

22. Keymel, S.; Kalka, C.; Rassaf, T.; Yeghiazarians, Y.; Kelm, M.; Heiss, C. Impaired endothelial progenitor cell function predicts age-dependent carotid intimal thickening. Basic Res. Cardiol. 2008, 103, 582-586.

23. Kirton, J.P.; Xu, Q. Endothelial precursors in vascular repair. Microvasc. Res. 2010, 79, 193-199.

24. Yubero-Serrano, E.M.; Delgado-Casado, N.; Delgado-Lista, J.; Perez-Martinez, P.; Tasset-Cuevas, I.; Santos-Gonzalez, M.; Caballero, J.; Garcia-Rios, A.; Marin, C.; Gutierrez-Mariscal, F.M.; et al. Postprandial antioxidant effect of the Mediterranean diet supplemented with coenzyme $\mathrm{Q}_{10}$ in elderly men and women. Age 2011, 33, 579-590.

25. Yubero-Serrano, E.M.; Garcia-Rios, A.; Delgado-Lista, J.; Delgado-Casado, N.; Perez-Martinez, P.; Rodriguez-Cantalejo, F.; Fuentes, F.; Cruz-Teno, C.; Tunez, I.; Tasset-Cuevas, I.; et al. Postprandial effects of the Mediterranean diet on oxidant and antioxidant status in elderly men and women. J. Am. Geriatr. Soc. 2011, 59, 938-940.

26. McCarty, M.F. A low-fat, whole-food vegan diet, as well as other strategies that down-regulate IGF-I activity, may slow the human aging process. Med. Hypotheses 2003, 60, 784-792.

27. Csiszar, A.; Labinskyy, N.; Pinto, J.T.; Ballabh, P.; Zhang, H.; Losonczy, G.; Pearson, K.; de Cabo, R.; Pacher, P.; Zhang, C.; et al. Resveratrol induces mitochondrial biogenesis in endothelial cells. Am. J. Physiol. Heart Circ. Physiol. 2009, 297, H13-H20.

28. Tang, Y.; Xu, J.; Qu, W.; Peng, X.; Xin, P.; Yang, X.; Ying, C.; Sun, X.; Hao, L. Resveratrol reduces vascular cell senescence through attenuation of oxidative stress by SIRT1/NADPH oxidase-dependent mechanisms. J. Nutr. Biochem. 2012, 23, 1410-1416.

29. Landberg, R.; Naidoo, N.; van Dam, R.M. Diet and endothelial function: From individual components to dietary patterns. Curr. Opin. Lipidol. 2012, 23, 147-155.

30. Kiecolt-Glaser, J.K.; Belury, M.A.; Andridge, R.; Malarkey, W.B.; Hwang, B.S.; Glaser, R. Omega-3 supplementation lowers inflammation in healthy middle-aged and older adults: A randomized controlled trial. Brain Behav. Immun. 2012, 26, 988-995.

31. Kiecolt-Glaser, J.K.; Epel, E.S.; Belury, M.A.; Andridge, R.; Lin, J.; Glaser, R.; Malarkey, W.B.; Hwang, B.S.; Blackburn, E. Omega-3 fatty acids, oxidative stress, and leukocyte telomere length: A randomized controlled trial. Brain Behav. Immun. 2013, 28, 16-24. 
32. Weiss, E.P.; Fontana, L. Caloric restriction: powerful protection for the aging heart and vasculature. Am. J. Physiol. Heart Circ. Physiol. 2011, 301, H1205-H1219.

33. Scoditti, E.; Calabriso, N.; Massaro, M.; Pellegrino, M.; Storelli, C.; Martines, G.; de Caterina, R.; Carluccio, M.A. Mediterranean diet polyphenols reduce inflammatory angiogenesis through MMP-9 and COX-2 inhibition in human vascular endothelial cells: A potentially protective mechanism in atherosclerotic vascular disease and cancer. Arch. Biochem. Biophys. 2012, 527, 81-89.

34. Mirabello, L.; Huang, W.Y.; Wong, J.Y.; Chatterjee, N.; Reding, D.; Crawford, E.D.; de Vivo, I.; Hayes, R.B.; Savage, S.A. The association between leukocyte telomere length and cigarette smoking, dietary and physical variables, and risk of prostate cancer. Aging Cell 2009, 8, 405-413.

35. Marin, C.; Delgado-Lista, J.; Ramirez, R.; Carracedo, J.; Caballero, J.; Perez-Martinez, P.; Gutierrez-Mariscal, F.M.; Garcia-Rios, A.; Delgado-Casado, N.; Cruz-Teno, C.; et al. Mediterranean diet reduces senescence-associated stress in endothelial cells. Age 2012, 34, 1309-1316.

36. Marin, C.; Ramirez, R.; Delgado-Lista, J.; Yubero-Serrano, E.M.; Perez-Martinez, P.; Carracedo, J.; Garcia-Rios, A.; Rodriguez, F.; Gutierrez-Mariscal, F.M.; Gomez, P.; et al. Mediterranean diet reduces endothelial damage and improves the regenerative capacity of endothelium. Am. J. Clin. Nutr. 2011, 93, 267-274.

37. Fernandez, J.M.; Rosado-Alvarez, D.; da Silva Grigoletto, M.E.; Rangel-Zuniga, O.A.; Landaeta-Diaz, L.L.; Caballero-Villarraso, J.; Lopez-Miranda, J.; Perez-Jimenez, F.; Fuentes-Jimenez, F. Moderate-to-high-intensity training and a hypocaloric Mediterranean diet enhance endothelial progenitor cells and fitness in subjects with the metabolic syndrome. Clin. Sci. 2012, 123, 361-373.

38. Perez-Martinez, P.; Garcia-Quintana, J.M.; Yubero-Serrano, E.M.; Tasset-Cuevas, I.; Tunez, I.; Garcia-Rios, A.; Delgado-Lista, J.; Marin, C.; Perez-Jimenez, F.; Roche, H.M.; et al. Postprandial oxidative stress is modified by dietary fat: Evidence from a human intervention study. Clin. Sci. 2010, 119, 251-261.

39. Cruz-Teno, C.; Perez-Martinez, P.; Delgado-Lista, J.; Yubero-Serrano, E.M.; Garcia-Rios, A.; Marin, C.; Gomez, P.; Jimenez-Gomez, Y.; Camargo, A.; Rodriguez-Cantalejo, F.; et al. Dietary fat modifies the postprandial inflammatory state in subjects with metabolic syndrome: the LIPGENE study. Mol. Nutr. Food Res. 2012, 56, 854-865.

40. Cassidy, A.; de Vivo, I.; Liu, Y.; Han, J.; Prescott, J.; Hunter, D.J.; Rimm, E.B. Associations between diet, lifestyle factors, and telomere length in women. Am. J. Clin. Nutr. 2011, 91, 1273-1280.

41. Farzaneh-Far, R.; Lin, J.; Epel, E.S.; Harris, W.S.; Blackburn, E.H.; Whooley, M.A. Association of marine omega-3 fatty acid levels with telomeric aging in patients with coronary heart disease. JAMA 2010, 303, 250-257.

42. Jung, K.J.; Lee, E.K.; Kim, J.Y.; Zou, Y.; Sung, B.; Heo, H.S.; Kim, M.K.; Lee, J.; Kim, N.D.; $\mathrm{Yu}, \mathrm{B} . \mathrm{P}$.; et al. Effect of short term calorie restriction on pro-inflammatory NF- $\mathrm{kB}$ and AP-1 in aged rat kidney. Inflamm. Res. 2009, 58, 143-150. 
43. Zou, Y.; Yoon, S.; Jung, K.J.; Kim, C.H.; Son, T.G.; Kim, M.S.; Kim, Y.J.; Lee, J.; Yu, B.P.; Chung, H.Y. Upregulation of aortic adhesion molecules during aging. J. Gerontol. A 2006, 61, 232-244.

44. Ungvari, Z.; Orosz, Z.; Labinskyy, N.; Rivera, A.; Xiangmin, Z.; Smith, K.; Csiszar, A. Increased mitochondrial $\mathrm{H}_{2} \mathrm{O}_{2}$ production promotes endothelial NF-kappaB activation in aged rat arteries. Am. J. Physiol. Heart Circ. Physiol. 2007, 293, H37-H47.

45. Csiszar, A.; Smith, K.; Labinskyy, N.; Orosz, Z.; Rivera, A.; Ungvari, Z. Resveratrol attenuates TNF-alpha-induced activation of coronary arterial endothelial cells: Role of NF-kappaB inhibition. Am. J. Physiol. Heart Circ. Physiol. 2006, 291, H1694-H1699.

46. Goraca, A. Assessment of total antioxidant capacity in human plasma. Folia Med. 2004, 46, $16-21$.

47. Hossain, M.; Qadri, S.M.; Liu, L. Inhibition of nitric oxide synthesis enhances leukocyte rolling and adhesion in human microvasculature. J. Inflamm. (Lond.) 2012, 9, 28.

48. Pacher, P.; Beckman, J.S.; Liaudet, L. Nitric oxide and peroxynitrite in health and disease. Physiol. Rev. 2007, 87, 315-424.

49. Mecocci, P.; Parnetti, L.; Romano, G.; Scarelli, A.; Chionne, F.; Cecchetti, R.; Polidori, M.C.; Palumbo, B.; Cherubini, A.; Senin, U. Serum anti-GFAP and anti-S100 autoantibodies in brain aging, Alzheimer's disease and vascular dementia. J. Neuroimmunol. 1995, 57, 165-170.

50. Pang, L.J.; Shao, J.Y.; Liang, X.M.; Xia, Y.F.; Zeng, Y.X. Mitochondrial DNA somatic mutations are frequent in nasopharyngeal carcinoma. Cancer Biol. Ther. 2008, 7, 198-207.

51. Hamilton, C.A.; Brosnan, M.J.; McIntyre, M.; Graham, D.; Dominiczak, A.F. Superoxide excess in hypertension and aging: A common cause of endothelial dysfunction. Hypertension 2001, 37, 529-534.

52. Yang, Y.M.; Huang, A.; Kaley, G.; Sun, D. eNOS uncoupling and endothelial dysfunction in aged vessels. Am. J. Physiol. Heart Circ. Physiol. 2009, 297, H1829-H1836.

53. Ungvari, Z.; Buffenstein, R.; Austad, S.N.; Podlutsky, A.; Kaley, G.; Csiszar, A. Oxidative stress in vascular senescence: lessons from successfully aging species. Front. Biosci. 2008, 13, 5056-5070.

54. Li, M.; Fukagawa, N.K. Age-related changes in redox signaling and VSMC function. Antioxid. Redox Signal. 2010, 12, 641-655.

55. Malinin, N.L.; West, X.Z.; Byzova, T.V. Oxidation as "the stress of life". Aging 2011, 3, 906-910.

56. Csiszar, A.; Wang, M.; Lakatta, E.G.; Ungvari, Z. Inflammation and endothelial dysfunction during aging: Role of NF-kappaB. J. Appl. Physiol. 2008, 105, 1333-1341.

57. Csiszar, A.; Toth, J.; Peti-Peterdi, J.; Ungvari, Z. The aging kidney: role of endothelial oxidative stress and inflammation. Acta Physiol. Hung. 2007, 94, 107-115.

58. Ungvari, Z.; Parrado-Fernandez, C.; Csiszar, A.; de Cabo, R. Mechanisms underlying caloric restriction and lifespan regulation: Implications for vascular aging. Circ. Res. 2008, 102, 519-528.

59. Loscalzo, J. Nitric oxide insufficiency, platelet activation, and arterial thrombosis. Circ. Res. 2001, 88, 756-762. 
60. Fukai, T. Extracellular SOD and aged blood vessels. Am. J. Physiol. Heart Circ. Physiol. 2009, 297, H10-H12.

61. Spier, S.A.; Delp, M.D.; Meininger, C.J.; Donato, A.J.; Ramsey, M.W.; Muller-Delp, J.M. Effects of ageing and exercise training on endothelium-dependent vasodilatation and structure of rat skeletal muscle arterioles. J. Physiol. 2004, 556, 947-958.

62. Bode-Boger, S.M.; Muke, J.; Surdacki, A.; Brabant, G.; Boger, R.H.; Frolich, J.C. Oral L-arginine improves endothelial function in healthy individuals older than 70 years. Vasc. Med. 2003, 8, 77-81.

63. Santhanam, L.; Christianson, D.W.; Nyhan, D.; Berkowitz, D.E. Arginase and vascular aging. J. Appl. Physiol. 2008, 105, 1632-1642.

64. Holowatz, L.A.; Thompson, C.S.; Kenney, W.L. L-Arginine supplementation or arginase inhibition augments reflex cutaneous vasodilatation in aged human skin. J. Physiol. 2006, 574, 573-581.

65. Rodriguez-Crespo, I.; Ortiz de Montellano, P.R. Human endothelial nitric oxide synthase: Expression in Escherichia coli, coexpression with calmodulin, and characterization. Arch. Biochem. Biophys. 1996, 336, 151-156.

66. Channon, K.M.; Watkins, H. Coronary artery disease genetics: Bigger is better. Eur. Heart J. 2004, 25, 900-901.

67. Eskurza, I.; Myerburgh, L.A.; Kahn, Z.D.; Seals, D.R. Tetrahydrobiopterin augments endothelium-dependent dilatation in sedentary but not in habitually exercising older adults. J. Physiol. 2005, 568, 1057-1065.

68. Juonala, M.; Viikari, J.S.; Alfthan, G.; Marniemi, J.; Kahonen, M.; Taittonen, L.; Laitinen, T.; Raitakari, O.T. Brachial artery flow-mediated dilation and asymmetrical dimethylarginine in the cardiovascular risk in young Finns study. Circulation 2007, 116, 1367-1373.

69. Schulze, F.; Maas, R.; Freese, R.; Schwedhelm, E.; Silberhorn, E.; Boger, R.H. Determination of a reference value for $N(\mathrm{G}), N(\mathrm{G})$-dimethyl-L-arginine in 500 subjects. Eur. J. Clin. Invest. 2005, $35,622-626$.

70. Bode-Boger, S.M.; Scalera, F.; Martens-Lobenhoffer, J. Asymmetric dimethylarginine (ADMA) accelerates cell senescence. Vasc. Med. 2005, 10, S65-S71.

71. Matz, R.L.; Schott, C.; Stoclet, J.C.; Andriantsitohaina, R. Age-related endothelial dysfunction with respect to nitric oxide, endothelium-derived hyperpolarizing factor and cyclooxygenase products. Physiol. Res. 2000, 49, 11-18.

72. Zhou, X.; Bohlen, H.G.; Unthank, J.L.; Miller, S.J. Abnormal nitric oxide production in aged rat mesenteric arteries is mediated by $\mathrm{NAD}(\mathrm{P}) \mathrm{H}$ oxidase-derived peroxide. Am. J. Physiol. Heart Circ. Physiol. 2009, 297, H2227-H2233.

73. Donato, A.J.; Gano, L.B.; Eskurza, I.; Silver, A.E.; Gates, P.E.; Jablonski, K.; Seals, D.R. Vascular endothelial dysfunction with aging: Endothelin-1 and endothelial nitric oxide synthase. Am. J. Physiol. Heart Circ. Physiol. 2009, 297, H425-H432.

74. Smith, A.R.; Visioli, F.; Frei, B.; Hagen, T.M. Age-related changes in endothelial nitric oxide synthase phosphorylation and nitric oxide dependent vasodilation: Evidence for a novel mechanism involving sphingomyelinase and ceramide-activated phosphatase 2A. Aging Cell 2006, 5, 391-400. 
75. LeBlanc, A.J.; Shipley, R.D.; Kang, L.S.; Muller-Delp, J.M. Age impairs Flk-1 signaling and NO-mediated vasodilation in coronary arterioles. Am. J. Physiol. Heart Circ. Physiol. 2008, 295, H2280-H2288.

76. Fujiyama, S.; Amano, K.; Uehira, K.; Yoshida, M.; Nishiwaki, Y.; Nozawa, Y.; Jin, D.; Takai, S.; Miyazaki, M.; Egashira, K.; et al. Bone marrow monocyte lineage cells adhere on injured endothelium in a monocyte chemoattractant protein-1-dependent manner and accelerate reendothelialization as endothelial progenitor cells. Circ. Res. 2003, 93, 980-989.

77. Ahrens, I.; Domeij, H.; Topcic, D.; Haviv, I.; Merivirta, R.M.; Agrotis, A.; Leitner, E.; Jowett, J.B.; Bode, C.; Lappas, M.; et al. Successful in vitro expansion and differentiation of cord blood derived CD34+ cells into early endothelial progenitor cells reveals highly differential gene expression. PLoS One 2011, 6, e23210.

78. Thum, T.; Hoeber, S.; Froese, S.; Klink, I.; Stichtenoth, D.O.; Galuppo, P.; Jakob, M.; Tsikas, D.; Anker, S.D.; Poole-Wilson, P.A.; et al. Age-dependent impairment of endothelial progenitor cells is corrected by growth-hormone-mediated increase of insulin-like growth-factor-1. Circ. Res. 2007, 100, 434-443.

79. Scheubel, R.J.; Zorn, H.; Silber, R.E.; Kuss, O.; Morawietz, H.; Holtz, J.; Simm, A. Age-dependent depression in circulating endothelial progenitor cells in patients undergoing coronary artery bypass grafting. J. Am. Coll. Cardiol. 2003, 42, 2073-2080.

80. Heiss, C.; Keymel, S.; Niesler, U.; Ziemann, J.; Kelm, M.; Kalka, C. Impaired progenitor cell activity in age-related endothelial dysfunction. J. Am. Coll. Cardiol. 2005, 45, 1441-1448.

81. Hill, J.M.; Zalos, G.; Halcox, J.P.; Schenke, W.H.; Waclawiw, M.A.; Quyyumi, A.A.; Finkel, T. Circulating endothelial progenitor cells, vascular function, and cardiovascular risk. N. Engl. J. Med. 2003, 348, 593-600.

82. He, T.; Joyner, M.J.; Katusic, Z.S. Aging decreases expression and activity of glutathione peroxidase-1 in human endothelial progenitor cells. Microvasc. Res. 2009, 78, 447-452.

83. Bruunsgaard, H.; Skinhoj, P.; Pedersen, A.N.; Schroll, M.; Pedersen, B.K. Ageing, tumour necrosis factor-alpha (TNF-alpha) and atherosclerosis. Clin. Exp. Immunol. 2000, 121, 255-260.

84. Bernardini, D.; Ballabio, E.; Mariotti, M.; Maier, J.A. Differential expression of EDF-1 and endothelial nitric oxide synthase by proliferating, quiescent and senescent microvascular endothelial cells. Biochim. Biophys. Acta 2005, 1745, 265-272.

85. Ma, F.X.; Zhou, B.; Chen, Z.; Ren, Q.; Lu, S.H.; Sawamura, T.; Han, Z.C. Oxidized low density lipoprotein impairs endothelial progenitor cells by regulation of endothelial nitric oxide synthase. J. Lipid Res. 2006, 47, 1227-1237.

86. Minamino, T.; Miyauchi, H.; Yoshida, T.; Tateno, K.; Komuro, I. The role of vascular cell senescence in atherosclerosis: antisenescence as a novel therapeutic strategy for vascular aging. Curr. Vasc. Pharmacol. 2004, 2, 141-148.

87. Blasco, M.A. Telomeres and human disease: Ageing, cancer and beyond. Nat. Rev. Genet. 2005, 6, 611-622.

88. Aviv, A.; Valdes, A.M.; Spector, T.D. Human telomere biology: Pitfalls of moving from the laboratory to epidemiology. Int. J. Epidemiol. 2006, 35, 1424-1429. 
89. Damjanovic, A.K.; Yang, Y.; Glaser, R.; Kiecolt-Glaser, J.K.; Nguyen, H.; Laskowski, B.; Zou, Y.; Beversdorf, D.Q.; Weng, N.P. Accelerated telomere erosion is associated with a declining immune function of caregivers of Alzheimer's disease patients. J. Immunol. 2007, 179, 4249-4254.

90. Babizhayev, M.A.; Savel'yeva, E.L.; Moskvina, S.N.; Yegorov, Y.E. Telomere length is a biomarker of cumulative oxidative stress, biologic age, and an independent predictor of survival and therapeutic treatment requirement associated with smoking behavior. Am. J. Ther. 2010, 18, e209-e26.

91. Brouilette, S.; Singh, R.K.; Thompson, J.R.; Goodall, A.H.; Samani, N.J. White cell telomere length and risk of premature myocardial infarction. Arterioscler. Thromb. Vasc. Biol. 2003, 23, 842-846.

92. Jaskelioff, M.; Muller, F.L.; Paik, J.H.; Thomas, E.; Jiang, S.; Adams, A.C.; Sahin, E.; Kost-Alimova, M.; Protopopov, A.; Cadinanos, J.; et al. Telomerase reactivation reverses tissue degeneration in aged telomerase-deficient mice. Nature 2011, 469, 102-106.

93. Sahin, E.; Colla, S.; Liesa, M.; Moslehi, J.; Muller, F.L.; Guo, M.; Cooper, M.; Kotton, D.; Fabian, A.J.; Walkey, C.; et al. Telomere dysfunction induces metabolic and mitochondrial compromise. Nature 2011, 470, 359-365.

94. Olivieri, F.; Recchioni, R.; Marcheselli, F.; Abbatecola, A.M.; Santini, G.; Borghetti, G.; Antonicelli, R.; Procopio, A.D. Cellular senescence in cardiovascular diseases: Potential age-related mechanisms and implications for treatment. Curr. Pharm. Des. 2012, 19, 1710-1719.

95. Boulanger, C.M.; Amabile, N.; Tedgui, A. Circulating microparticles: A potential prognostic marker for atherosclerotic vascular disease. Hypertension 2006, 48, 180-186.

96. Sabatier, F.; Roux, V.; Anfosso, F.; Camoin, L.; Sampol, J.; Dignat-George, F. Interaction of endothelial microparticles with monocytic cells in vitro induces tissue factor-dependent procoagulant activity. Blood 2002, 99, 3962-3970.

97. Baron, M.; Boulanger, C.M.; Staels, B.; Tailleux, A. Cell-derived microparticles in atherosclerosis: Biomarkers and targets for pharmacological modulation? J. Cell. Mol. Med. 2011, 16, 1365-1376.

98. Gyorgy, B.; Szabo, T.G.; Pasztoi, M.; Pal, Z.; Misjak, P.; Aradi, B.; Laszlo, V.; Pallinger, E.; Pap, E.; Kittel, A.; et al. Membrane vesicles, current state-of-the-art: Emerging role of extracellular vesicles. Cell. Mol. Life Sci. 2011, 68, 2667-2688.

99. Esposito, K.; Ciotola, M.; Schisano, B.; Gualdiero, R.; Sardelli, L.; Misso, L.; Giannetti, G.; Giugliano, D. Endothelial microparticles correlate with endothelial dysfunction in obese women. J. Clin. Endocrinol. Metab. 2006, 91, 3676-3679.

100. McDonald, A.P.; Meier, T.R.; Hawley, A.E.; Thibert, J.N.; Farris, D.M.; Wrobleski, S.K.; Henke, P.K.; Wakefield, T.W.; Myers, D.D., Jr. Aging is associated with impaired thrombus resolution in a mouse model of stasis induced thrombosis. Thromb. Res. 2010, 125, 72-78.

101. Previtali, E.; Bucciarelli, P.; Passamonti, S.M.; Martinelli, I. Risk factors for venous and arterial thrombosis. Blood Transfus. 2011, 9, 120-138.

102. Brodsky, S.V.; Zhang, F.; Nasjletti, A.; Goligorsky, M.S. Endothelium-derived microparticles impair endothelial function in vitro. Am. J. Physiol. Heart Circ. Physiol. 2004, 286, H1910-H1915. 
103. Burger, D.; Montezano, A.C.; Nishigaki, N.; He, Y.; Carter, A.; Touyz, R.M. Endothelial microparticle formation by angiotensin II is mediated via Ang II receptor type I/NADPH oxidase/ Rho kinase pathways targeted to lipid rafts. Arterioscler. Thromb. Vasc. Biol. 2011, 31, 1898-1907.

104. Terrisse, A.D.; Puech, N.; Allart, S.; Gourdy, P.; Xuereb, J.M.; Payrastre, B.; Sie, P. Internalization of microparticles by endothelial cells promotes platelet/endothelial cell interaction under flow. J. Thromb. Haemost. 2010, 8, 2810-2819.

105. Yang, C.; Mwaikambo, B.R.; Zhu, T.; Gagnon, C.; Lafleur, J.; Seshadri, S.; Lachapelle, P.; Lavoie, J.C.; Chemtob, S.; Hardy, P. Lymphocytic microparticles inhibit angiogenesis by stimulating oxidative stress and negatively regulating VEGF-induced pathways. Am. J. Physiol. Regul. Integr. Comp. Physiol. 2008, 294, R467-R476.

106. Essayagh, S.; Xuereb, J.M.; Terrisse, A.D.; Tellier-Cirioni, L.; Pipy, B.; Sie, P. Microparticles from apoptotic monocytes induce transient platelet recruitment and tissue factor expression by cultured human vascular endothelial cells via a redox-sensitive mechanism. Thromb. Haemost. 2007, 98, 831-837.

107. Klonizakis, M.; Alkhatib, A.; Middleton, G.; Smith, M.F. Mediterranean diet- and exercise-induced improvement in age-dependent vascular activity. Clin. Sci. 2012, 124, 579-587.

108. Dal-Ros, S.; Bronner, C.; Auger, C.; Schini-Kerth, V.B. Red wine polyphenols improve an established aging-related endothelial dysfunction in the mesenteric artery of middle-aged rats: Role of oxidative stress. Biochem. Biophys. Res. Commun. 2012, 419, 381-387.

109. Zuchi, C.; Ambrosio, G.; Luscher, T.F.; Landmesser, U. Nutraceuticals in cardiovascular prevention: Lessons from studies on endothelial function. Cardiovasc. Ther. 2010, 28, 187-201.

110. Chiva-Blanch, G.; Urpi-Sarda, M.; Ros, E.; Arranz, S.; Valderas-Martinez, P.; Casas, R.; Sacanella, E.; Llorach, R.; Lamuela-Raventos, R.M.; Andres-Lacueva, C.; et al. Dealcoholized red wine decreases systolic and diastolic blood pressure and increases plasma nitric oxide: Short communication. Circ. Res. 2012, 111, 1065-1068.

111. Torabian, S.; Haddad, E.; Rajaram, S.; Banta, J.; Sabate, J. Acute effect of nut consumption on plasma total polyphenols, antioxidant capacity and lipid peroxidation. J. Hum. Nutr. Diet 2009, $22,64-71$.

112. Carlsen, M.H.; Halvorsen, B.L.; Holte, K.; Bohn, S.K.; Dragland, S.; Sampson, L.; Willey, C.; Senoo, H.; Umezono, Y.; Sanada, C.; et al. The total antioxidant content of more than 3100 foods, beverages, spices, herbs and supplements used worldwide. Nutr. J. 2010, 9, 3.

113. Sun, Y.; Ma, A.; Li, Y.; Han, X.; Wang, Q.; Liang, H. Vitamin E supplementation protects erythrocyte membranes from oxidative stress in healthy Chinese middle-aged and elderly people. Nutr. Res. 2012, 32, 328-334.

114. Thomas, D.R. Vitamins in aging, health, and longevity. Clin. Interv. Aging 2006, 1, 81-91.

115. Obrenovich, M.E.; Nair, N.G.; Beyaz, A.; Aliev, G.; Reddy, V.P. The role of polyphenolic antioxidants in health, disease, and aging. Rejuvenation Res. 2010, 13, 631-643.

116. Obrenovich, M.E.; Li, Y.; Parvathaneni, K.; Yendluri, B.B.; Palacios, H.H.; Leszek, J.; Aliev, G. Antioxidants in health, disease and aging. CNS Neurol. Disord. Drug Targets 2011, 10, 192-207.

117. Jennings, B.J.; Ozanne, S.E.; Dorling, M.W.; Hales, C.N. Early growth determines longevity in male rats and may be related to telomere shortening in the kidney. FEBS Lett. 1999, 448, 4-8. 
118. Shen, J.; Gammon, M.D.; Terry, M.B.; Wang, Q.; Bradshaw, P.; Teitelbaum, S.L.; Neugut, A.I.; Santella, R.M. Telomere length, oxidative damage, antioxidants and breast cancer risk. Int. J. Cancer 2009, 124, 1637-1643.

119. Erusalimsky, J.D.; Skene, C. Mechanisms of endothelial senescence. Exp. Physiol. 2009, 94, 299-304.

120. Meydani, A.; Ahmed, T.; Meydani, S.N. Aging, nutritional status, and infection in the developing world. Nutr. Rev. 2005, 63, 233-246.

121. Esposito, K.; di Palo, C.; Maiorino, M.I.; Petrizzo, M.; Bellastella, G.; Siniscalchi, I.; Giugliano, D. Long-term effect of mediterranean-style diet and calorie restriction on biomarkers of longevity and oxidative stress in overweight men. Cardiol. Res. Pract. 2011, 2011, 293916.

122. Everitt, A.V.; Hilmer, S.N.; Brand-Miller, J.C.; Jamieson, H.A.; Truswell, A.S.; Sharma, A.P.; Mason, R.S.; Morris, B.J.; le Couteur, D.G. Dietary approaches that delay age-related diseases. Clin. Interv. Aging 2006, 1, 11-31.

123. Pandey, K.B.; Rizvi, S.I. Plant polyphenols as dietary antioxidants in human health and disease. Oxid. Med. Cell. Longev. 2009, 2, 270-278.

124. Visioli, F.; Bogani, P.; Grande, S.; Galli, C. Mediterranean food and health: building human evidence. J. Physiol. Pharmacol. 2005, 56, 37-49.

125. Hulsmans, M.; Holvoet, P. The vicious circle between oxidative stress and inflammation in atherosclerosis. J. Cell. Mol. Med. 2011, 14, 70-78.

(C) 2013 by the authors; licensee MDPI, Basel, Switzerland. This article is an open access article distributed under the terms and conditions of the Creative Commons Attribution license (http://creativecommons.org/licenses/by/3.0/). 